\title{
Matrix Metalloproteinase Gene Delivery for Liver Fibrosis
}

\author{
Yuji limuro $^{1}$ and David A. Brenner ${ }^{2}$
}

Received February 6, 2007; accepted April 9, 2007; published online June 19, 2007

\begin{abstract}
The resolution of advanced liver fibrosis has been recently recognized to be possible, if the causative stimuli are successfully removed. However, whether complete resolution from cirrhosis, the end stage of liver fibrosis, can be achieved is still questionable. Delivery of interstitial collagenases, such as matrix metalloproteinase (MMP)-1, in the liver could be an attractive strategy to treat advanced hepatic fibrosis from the view point that the imbalance between too few interstitial collagenases and too many of their inhibitors is the main obstacle to the resolution from fibrosis. Remodeling of hepatic extracellular matrix by delivered interstitial collagenases also facilitates the disappearance of activated hepatic stellate cells, the main matrix-producing cells in the liver, and promotes the proliferation of hepatocytes. This review will focus on the impact of the gene delivery of MMPs for the treatment of advanced liver fibrosis while discussing other current therapeutic strategies for liver fibrosis, and on the need for the development of a safe and effective delivery system of MMPs.
\end{abstract}

KEY WORDS: gene delivery; hepatic stellate cells; liver fibrosis; MMP; TIMP.

\section{INTRODUCTION}

Liver fibrosis results from continuous damage to the liver, including viral hepatitis, alcohol abuse, drugs, metabolic diseases involving an overload of iron or copper, autoimmune diseases, or congenital abnormalities $(1,2)$. The end stage of liver fibrosis, cirrhosis, is characterized by increased deposition and altered composition of the ECM and the appearance of regenerative nodules $(3,4)$, accompanied by hepatic failure and portal hypertension (5). This represents an enormous worldwide healthcare problem.

From a treatment viewpoint, several approaches have successfully prevented the progression of liver fibrosis in animal models. However, because fibrotic liver disease may not present clinically until an advanced or cirrhotic stage, the possibility of reversing established fibrosis is an essential issue. Advanced hepatic fibrosis had been believed to be a passive and irreversible process due to the collapse of the hepatic parenchyma and its substitution with collagen-rich tissue (6). Recently, however, it is thought that hepatic fibrosis may be reversible if the underlying injurious stimuli are removed. Indeed, some investigators have reported improvement in liver fibrosis and cirrhosis in selective patients with effective antiviral therapies in chronic viral hepatitis $(7,8)$ and with surgical decompression of secondary biliary fibrosis (9), suggesting a capacity for recovery even

\footnotetext{
${ }^{1}$ First Department of Surgery, Hyogo College of Medicine, 1-1 Mukogawa-cho, Nishinomiya, Hyogo 663-8501, Japan.

${ }^{2}$ Department of Medicine, College of Physicians and Surgeons, Columbia University, New York, NY, USA.

${ }^{3}$ To whom correspondence should be addressed. (e-mail: siimuro@ hyo-med.ac.jp)
}

from established cirrhosis. Transplantation is another effective treatment for advanced cirrhosis $(10,11)$ but is limited by the number of available donor organs. Therefore, effective antifibrotic treatments for established liver fibrosis are earnestly required, and biotechnology and pharmaceutical companies are increasingly interested in developing new antifibrotic therapies.

\section{PATHOGENESIS OF LIVER FIBROSIS}

Liver fibrosis is associated with major alterations in both the quantity and composition of the extracellular matrix (ECM) $(3,4)$. Accumulation of ECM, including fibrillar collagens, fibronectin, laminin, hyaluronan, and proteoglycans, results from both increased synthesis and decreased degradation (12).

Hepatic stellate cells (HSC) are believed to be the main ECM-producing cells in the injured liver (1), while portal fibroblasts also play important roles in several kinds of liver fibrosis $(13,14)$. In the normal liver, HSC reside in the space of Disse and are the major storage sites of vitamin A. In injured areas of the liver, HSC activate or transdifferentiate into myofibroblast-like cells, expressing contractile proteins and secreting large amounts of ECM, especially fibrillar collagens (type I and type III) $(15,16)$. Many researchers are now investigating the mechanisms mediating the activation of HSC, and activated nonparenchymal cells (NPC), such as Kupffer cells, are believed to play important roles in the mechanism $(17,18)$.

The decreased activity of ECM-removing MMPs is mainly due to an increased expression of their specific inhibitors, tissue inhibitors of metalloproteinase (TIMPs). The key enzymes in the degradation of fibrillar collagens are matrix metalloproteinase (MMP)-1 in humans and MMP-13 
in rodents $(19,20)$. However, during fibrogenesis, the expression of MMP-1 or MMP-13 is very limited, whereas that of MMP-2 increases $(21,22)$. On the other hand, fibrotic livers have high expression of the TIMPs, including TIMP-1 and TIMP-2 (23-25). Thus, there is a combination of low expression of interstitial collagenases and high TIMPs that prevents the degradation of the fibrillar collagens. Moreover, it has been recently well documented that fibrillar collagens act as a survival factor for activated HSC. An in vitro study has shown that HSC are activated on collagen type I, whereas they are quiescent on Matrigel (26), implying that signals from the ECM through some types of adhesion molecules, such as integrins, play critical roles in HSC activation. TIMPs are also reported to block HSC apoptosis in fibrotic livers $(27,28)$. Thus, the imbalance between too few MMPs, too much ECM and too many TIMPs possibly account for the advanced liver fibrosis and the failure to resolve the fibrous scar (Fig. 1).

\section{RESOLUTION OF LIVER FIBROSIS}

Recently, many researchers have focused on the reversal of hepatic fibrosis $(29,30)$. As mentioned above, recent evidence indicates that even advanced fibrosis is reversible, in contrast with the traditional view that cirrhosis is an irreversible disease (6). Increased collagenolytic activity is a major mechanism of fibrosis resolution (31), and fibrillar collagens (type I and III) are degraded by interstitial MMPs. According to several animal models of liver fibrosis resolution, the expression of TIMPs rapidly decreases while interstitial MMPs continue to be expressed during the resolution, resulting in increased MMP activity and consequent matrix degradation within the liver $(27,29,30)$.

Together with these changes in MMP activity, the apoptosis of activated HSC has been observed in the resolution process of hepatic fibrosis $(29,32,33)$. In a progressive fibrogenic process, activated HSC secrete large amounts of ECM. When the injurious stimulus is withdrawn and the survival factors for activated HSC, including soluble factors and ECM, are partially removed, the loss of activated HSC by apoptosis is thought to occur. HSC apoptosis, in turn, facilitates the remodeling process by removing the major cellular source of collagen and TIMPs.

However, it is still questionable whether the complete resolution of advanced liver fibrosis is possible. Data from animal experiments indicate that resolution from an extensive micronodular to an attenuated macronodular cirrhosis is possible when injurious stimuli are removed, while complete resolution is limited by ECM cross-linking and a failure of activated HSC to undergo apoptosis (30). Therefore, it seems that treatments possessing MMP activity against matrix-cross linking are necessary for complete, or nearly complete, histologic resolution from advanced cirrhosis.
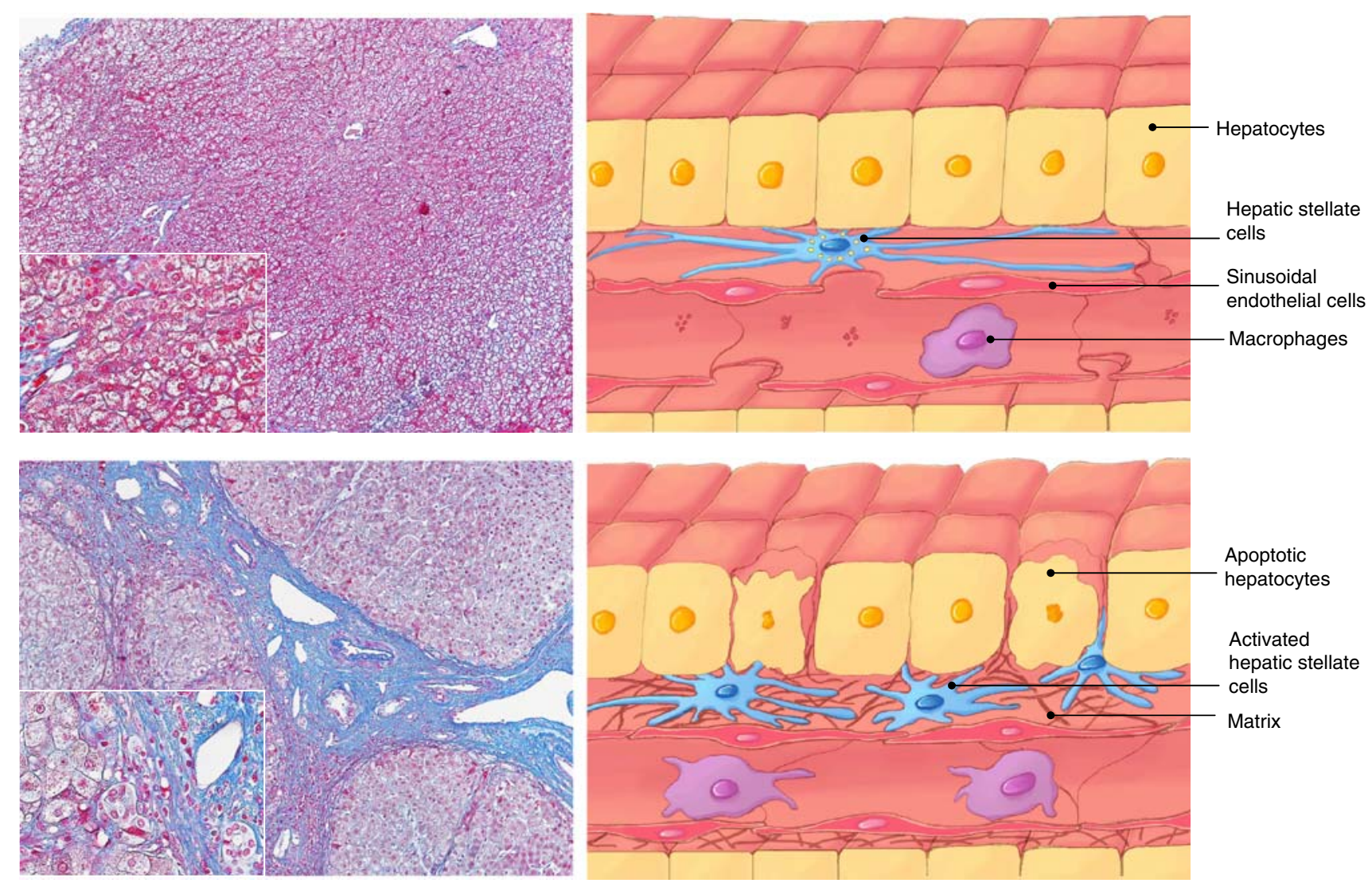

Fig. 1. Azan-Mallory staining of human samples from normal (top) and cirrhotic (bottom) livers. Blue-stained area represents collagen and reticular fibers. Regenerative nodules surrounded by abundant fibrous band are observed in the cirrhotic liver (bottom). Schematic changes in the hepatic architecture between normal (right top) and cirrhotic (right bottom) livers are also shown. 


\section{RECENT ADVANCES AND CHALLENGES IN TREATMENT OF LIVER FIBROSIS}

Removal of the underlying stimulus is believed to be the most effective strategy for the treatment of hepatic fibrosis. Meanwhile, alternative approaches to treat this disease at earlier stages are currently in progress in consideration of the mechanism of liver fibrosis and its resolution (Table I).

\section{Anti-inflammatory Approaches}

Hepatic inflammation invariably precedes fibrosis as mentioned above. Consequently, a number of anti-inflammatory agents have been evaluated intensively. Corticosteroids have been used to successfully treat autoimmune hepatitis, and also shown to improve survival and reduced progression to cirrhosis in selected patients with severe alcoholic hepatitis (34) with no benefit in the treatment of primary biliary cirrhosis (PBC) (35). Colchicine, a well-known anti-inflammatory plant extract, has been used as an antifibrotic agent on the basis of a beneficial effect in experimental fibrosis models and cirrhotic patients (36), although there is some discrepancy between the subsequently reported study (37). Other anti-inflammatory agents such as malotilate (38) and octreotide (39) have been reported to be effective for the treatment of liver fibrosis in animal models, but promising results with these agents in cirrhotic patients remains obscure. Antagonism of pro-inflammatory cytokines is also an attractive approach. An antibody against $\mathrm{TNF} \alpha$ (40) or a soluble TNF $\alpha$ receptor (41) has shown potential for reducing liver injury in experimental models. However, randomized controlled trial concerning the effect of the humanized monoclonal anti-TNF $\alpha$ antibody, infliximab, in acute alcoholic hepatitis was stopped early due to an excess of deaths through sepsis (42). Thalidomide has also shown its antagonistic effect against $\mathrm{TNF} \alpha$, and been shown to be beneficial in experimental models of liver injury $(43,44)$. Blockade of IL-1, another important pro-inflammatory cytokine, using IL-1 receptor antagonist reduced liver fibrosis in an experimental model (45). IL-10 also has potent anti-inflammatory and antifibrotic effects. Recombinant IL-10 reduced inflammation and fibrosis in patients with chronic hepatitis $\mathrm{C}$, but increased HCV viral burden (46).

\section{Inhibition of HSC Activation and Proliferation}

Hepatic stellate cells (HSC) are believed to be the main ECM-producing cells in the injured liver. Therefore, inhibition of HSC activation or proliferation is critically important in the treatment of liver fibrosis.

Many kinds of antioxidants have been investigated because oxidative stress can induce HSC activation (47). Vitamin E inhibited HSC activation in several experimental models $(48,49)$, and also in a pilot study of humans with chronic hepatitis C infection (50). Polyenylphosphatidylcholine, an extract from soybean, has shown beneficial effect in ethanol- (51) or carbon tetrachloride $\left(\mathrm{CCl}_{4}\right)$-induced (52) experimental hepatic fibrosis. Other antioxidants, such as silymarin (53), $n$-acetylcysteine (54,55), and S-adenosyl-Lmethionine (56) can inhibit HSC activation in experimental models of liver fibrosis, but silymarin had no effect in another controlled trial in human (57).

Table I. Therapeutic Strategies for the Treatment of Liver Fibrosis

\begin{tabular}{|c|c|}
\hline Therapeutical Target & Agent \\
\hline Supress inflammation & $\begin{array}{l}\text { corticosteroids } \\
\text { colchicine } \\
\text { malotilate } \\
\text { octreotide } \\
\text { TNF } \boldsymbol{\alpha} \text { antagonist (e.g. anti- TNF } \boldsymbol{\alpha} \text { antibody, soluble TNF } \boldsymbol{\alpha} \text { receptor, thalidomide) } \\
\text { IL- } 1 \text { receptor antagonist } \\
\text { recombinant IL- } 10\end{array}$ \\
\hline Inhibit HSC activation and proliferation & $\begin{array}{l}\text { antioxidants (e.g. vitamin E, phosphatidylcholine, } \\
\quad \text { silymarin, } n \text { - acetylcysteine, S- adenosyl- L-methionine) } \\
\text { tyrosine kinase inhibitors (e.g. genistein, imatinib mesylate) } \\
\text { soluble dominant- negative form of the PDGF receptor } \\
\text { PI3K inhibitors (e.g. wortmanin, canrenone, LY294002) } \\
\text { Ras inhibitor S- farnesylthiosalicylate } \\
\text { ROCK inhibitor Y- } 27632 \\
\text { TGF- } \beta \text { antagonist (e.g. camostat, soluble or dominant- negative } \\
\text { TGF- } \beta \text { type II receptors, TGF } \beta 1 \text { antisense mRNA, smad7, HGF) } \\
\text { AT receptor inhibitors (e.g. losartan, candesartan, olmesartan) } \\
\text { ACE inhibitors (e.g., peridinopril, captopril) } \\
\text { Trichostatin A }\end{array}$ \\
\hline Stimulate HSC apoptosis & $\begin{array}{l}\text { Fas ligand } \\
\text { NGF } \\
\text { gliotoxin } \\
\text { sulfasalazine }\end{array}$ \\
\hline Enhance matrix degradation & $\begin{array}{l}\text { MMPs } \\
\text { TIMP antagonist } \\
\text { uPA } \\
\text { bone marrow transplantation }\end{array}$ \\
\hline
\end{tabular}


Numerous mitogens and cytokines have been implicated in hepatic fibrogenesis, promoting HSC proliferation or stimulating ECM production by HSC. Platelet-derived growth factor (PDGF) is a powerful mitogen for HSC (58), and its signaling pathway can be targeted for fibrosis therapy. Inhibition of the PDGF receptor using tyrosine kinase inhibitors such as genistein and imatinib mesylate blocked HSC activation and proliferation in vitro or in vivo $(59,60)$. A soluble dominant-negative form of the PDGF receptor showed similar results in bile duct-ligated rats (61). PI3 K, a downstream effecter of PDGF signaling, has also been studied as therapeutic target. Inhibitors of PI3 K such as wortmanin, canrenone, and LY294002 suppressed HSC migration and proliferation (62-64). The small GTPase Ras can be activated by PDGF to lead to cellular proliferation and migration, and the Ras inhibitor S-farnesylthiosalicylate suppressed HSC proliferation and migration and attenuated thioacetamide-induced liver fibrosis in rats (65). A Rasrelated GTPase, RhoA, is also implicated in HSC activation and treatment with an inhibitor of Rho's associated kinase ROCK, Y-27632, blocked HSC activation and proliferation in vivo and in vitro $(66,67)$.

TGF- $\beta 1$ is one of the most profibrogenic cytokines and is a potent activator of HSC. Several inhibitors of the TGF- $\beta$ pathway have been effective in experimental models of liver fibrosis. These include camostat, a serine protease inhibitor that prevents release of latent TGF- $\beta$ (68), soluble or dominant-negative TGF- $\beta$ type II receptors $(69,70)$, adenoviral expression of TGF- $\beta 1$ antisense mRNA (71), and gene transfer of smad7 that blocks TGF- $\beta$ intracellular signaling (72). However, no anti-TGF- $\beta$ strategy has been studied in human. Hepatocyte growth factor (HGF) has also shown its anti-fibrogenic effect in experimental models. Recombinant HGF and gene therapy with HGF cDNA promoted regression of fibrosis in vivo (73,74), suppressing TGF- $\beta$ expression and up-regulating MMP activity.

Angiotensin-II (AT-II) is a vasoconstrictive cytokine in the rennin-angiotensin system, which has been shown to be associated with HSC activation and fibrosis (75). A variety of angiotensin-I (AT-I) and -II receptor inhibitors such as losartan, candesartan, and olmesartan (76-78), and inhibitors of angiotensin-converting enzyme (57) such as peridinopril and captopril $(77,79)$ have also shown beneficial effects in animal models of liver fibrosis.

Meanwhile, histone deacetylation is a key gene regulatory process during $\mathrm{HSC}$ activation. Trichostatin A, a deacetylase inhibitor, reduced experimentally HSC activation in vitro (80).

\section{Stimulation of HSC Apoptosis}

Spontaneous resolution of liver fibrosis is associated with apoptosis of HSC as described above, so induction of HSC apoptosis could be make a useful anti-fibrotic therapy. HSC express a number of cell-surface death receptors, including Fas, TNFa receptor, and nerve growth factor (NFG) receptor. Activation of such death receptors following exposure to Fas ligand (81) or NGF (82) stimulated HSC apoptosis in vitro. Nuclear factor (NF)- $\mathrm{K}$ B is a transcription factor which can induce transcription of anti-apoptotic genes, and NF- $\kappa \mathrm{B}$ protects HSC from apoptosis. Thus inhibition of $\mathrm{NF}-\kappa \mathrm{B}$ in HSC can promote HSC apoptosis. A fungal metabolite gliotoxin has been shown to promote HSC apoptosis, and it accelerated recovery from experimental liver fibrosis

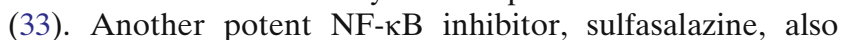
increased HSC apoptosis in vitro and in vivo (83). Ras inhibitor, S-farnesylthiosalicylate, also induced HSC apoptosis in TAA-induced established liver fibrosis (84).

\section{Promotion of Matrix Degradation}

Animal experiments suggest that total degradation of fibrous scar observed in advanced liver fibrosis, cirrhosis, could be impossible even if causative stimuli are successfully removed (30). Therefore, some anti-fibrotic therapy targeting the existing fibrous scar is required. Such strategies will be discussed in detail later in this review.

\section{Bone Marrow Transplantation as an Anti-fibrotic Therapy}

Recruitment of bone marrow-derived cells (BMC) into a variety of injured organs and differentiation of these cells into organ specific cells has been reported in the last few years. As for liver fibrosis, BMC has been reported to participate in the remodeling process during fibrosis resolution, and bone marrow transplantation has proved to be an attractive anti-fibrotic therapy (85). The molecular mechanism underlying such BMC-related matrix degradation possibly includes MMP activities $(85,86)$. Meanwhile, there is another aspect of BMC in liver fibrosis. Several studies have shown that $\mathrm{BMC}$ also participate in fibrogenesis in the liver (87-89), so more detailed analysis of the role of BMC in liver fibrosis is required.

\section{REMODELING OF EXTRACELLULAR MATRIX BY DELIVERING INTERSTITIAL MMPS}

In human studies, partial resolution of cirrhosis, such as resolution from an extensive micronodular to an attenuated macronodular cirrhosis, has been reported, if the fibrogenic stimuli are successfully removed $(7,90)$, suggesting the current best treatment for hepatic fibrosis is the removal of the underlying injurious causes. However, many clinicians may feel that advanced cirrhosis cannot return to mild fibrosis even if the ongoing fibrogenic stimuli have appeared to resolve or diminish during their follow-up observation. Accordingly, a more promising strategy might require other approaches in addition to the simple removal of the underlying causes for the treatment of advanced liver fibrosis or cirrhosis, especially in humans.

Molecular studies of the expression of mRNA for MMPs have shown that they are expressed in the liver even in cirrhosis, but their activity is suppressed by powerful specific inhibitors, TIMPs (91). Therefore, it is speculated that the potential for matrix degradation is present even in advanced cirrhosis. Manipulation of the imbalance between too few interstitial collagenases and too many TIMPs may possibly facilitate matrix degradation in fibrotic or cirrhotic livers, resulting in the resolution of the fibrosis.

There are logically two kinds of strategy to manipulate the imbalance between too few interstitial collagenases and 
too many TIMPs, leading to up-regulation of collagenase activity in fibrotic livers. One possible approach is the overexpression of interstitial MMPs in the livers, while another possibility is the inhibition of the excessive amount of TIMPs. In this review, the authors have focused on the former approach.

Several types of MMPs can digest fibrillar collagens; however, the most potent MMPs against these collagens are collagenases including MMP-1, MMP-8, and MMP-13 (92). Delivery of collagenases into advanced liver fibrosis has been reported by us and others using experimental animal models $(93,94)$. In our experiment, a complementary DNA encoding human pro-MMP-1 was delivered into established liver fibrosis using an adenoviral vector in a rat model (Fig. 2a). In that experiment, we tested our hypothesis that the transient manipulation of the imbalance between collageneses and TIMPs might attenuate established liver fibrosis induced by long-term treatment with thioacetamide (TAA). Long term administration of TAA has been reported to result in a characteristic lesion in rat liver, which corresponds to cirrhosis-like patterns of micronodular cirrhosis type. During its development a reproducible temporal course of biochemical and morphological changes can be recognized. After withdrawal of the toxic agent this lesion persists for at least 2 months (95). Western blot analysis with liver tissue homogenates showed that the delivery of human pro-MMP-1 complementary DNA by Ad5MMP- $1\left(5 \times 10^{9}\right.$ pfu per rat intravenously) successfully expressed pro-MMP-1 in all livers infected with Ad5MMP-1. Moreover, a significant amount of the active form of MMP-1 (41 kilodaltons) was also detected in this assay, indicating that the expressed pro-MMP-1 protein was gradually converted to the active form in vivo (Fig. 2b). One week after their last TAA treatment, the rats were infected with Ad5MMP-1 or Ad5LacZ, a control adenovirus $\left(5 \times 10^{9}\right.$ pfu per rat). Histological changes in the liver were examined at 2 and 4 weeks after the infection. The control Ad5LacZ had no obvious effect on the established liver fibrosis, which developed after 7 weeks of TAA treatment (Fig. 3a). After the Ad5MMP-1 infection, the fibrosis was significantly attenuated by 2 weeks and remained attenuated by 4 weeks, as indicated by Masson's trichrome staining (Fig. 3b). Preferential target cells in the liver following adenovirus-mediated gene transfer are generally hepatocytes as well known. Indeed, main target cells in our experiment were also hepatocytes (96), while human MMP-1 protein expression was observed rather diffusely because the expressed MMP-1 was secreted out of the infected cells.

Notably, in Ad5MMP-1-infected rats, the area of $\alpha$-SMApositive cells (a marker of activated HSC) dramatically decreased at 2 weeks, whereas infection with Ad5LacZ had no effect (Fig. 3c, d). A significant decrease in the $\alpha$-SMA-positive area was observed only in the Ad5MMP-1-infected animals, indicating that degradation of fibrillar collagens because of MMP-1 overexpression in the liver can lead to a decrease in the number of activated HSC. This phenomenon is consistent with the hypothesis that the loss of survival factor, such as fibrillar ECM, facilitates the disappearance, or apoptosis, of activated HSC, which in turn leads to lower expression of TIMPs and ECM, resulting in the resolution of liver fibrosis.

Another key observation in our study was that the proliferation of hepatocytes was induced by MMP-1 expression in the liver. Degradation of fibrillar collagens due to MMP-1 overexpression possibly affects the interaction between ECM and hepatocytes. Because hepatocytes are known to be responsive to the biophysical state of ECM $(97,98)$, modification of their interaction possibly stimulates a

Human pro-MMP-1 cDNA

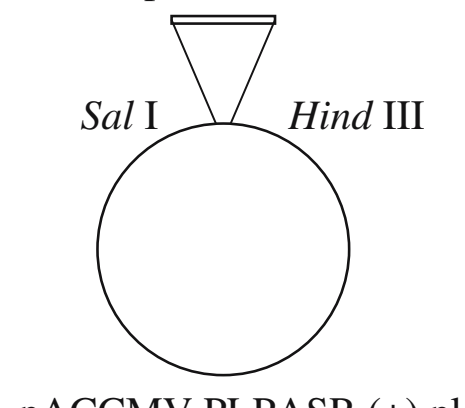

pACCMV.PLPASR (+) plasmid



\section{E1-deleted adenovirus type 5 DNA}

$\mathrm{b}$

\section{Homologous} recombination



ProMMP-1 MMP-1
Ad5MMP-1

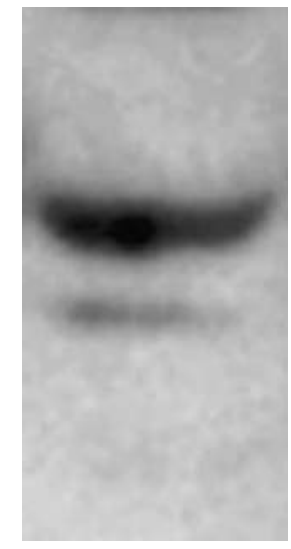

Fig. 2. a Schema of construction of adenovirus carrying human pro-MMP-1 cDNA (Ad5MMP-1). Plasmid pRc/CMV-pro-MMP-1, which contains a human pro-MMP-1 complementary DNA, was subcloned into the SalI/HindIII site of the pACCMV.PLPASR (+) plasmid to construct the plasmid pACCMV/MMP-1, in which pro-MMP-1 is driven by the cytomegalovirus promoter/enhancer. The recombinant adenovirus was then constructed by cotransfection of the 293 embryonic human kidney cell line with the pACCMV/MMP-1 plasmid plus the purified fragment of ClaI-digested DNA from E1-deleted adenovirus type 5 (Ad5). b Western blotting for human pro-MMP-1 and MMP-1 using liver homogenate obtained from rats infected with Ad5MMP-1. 

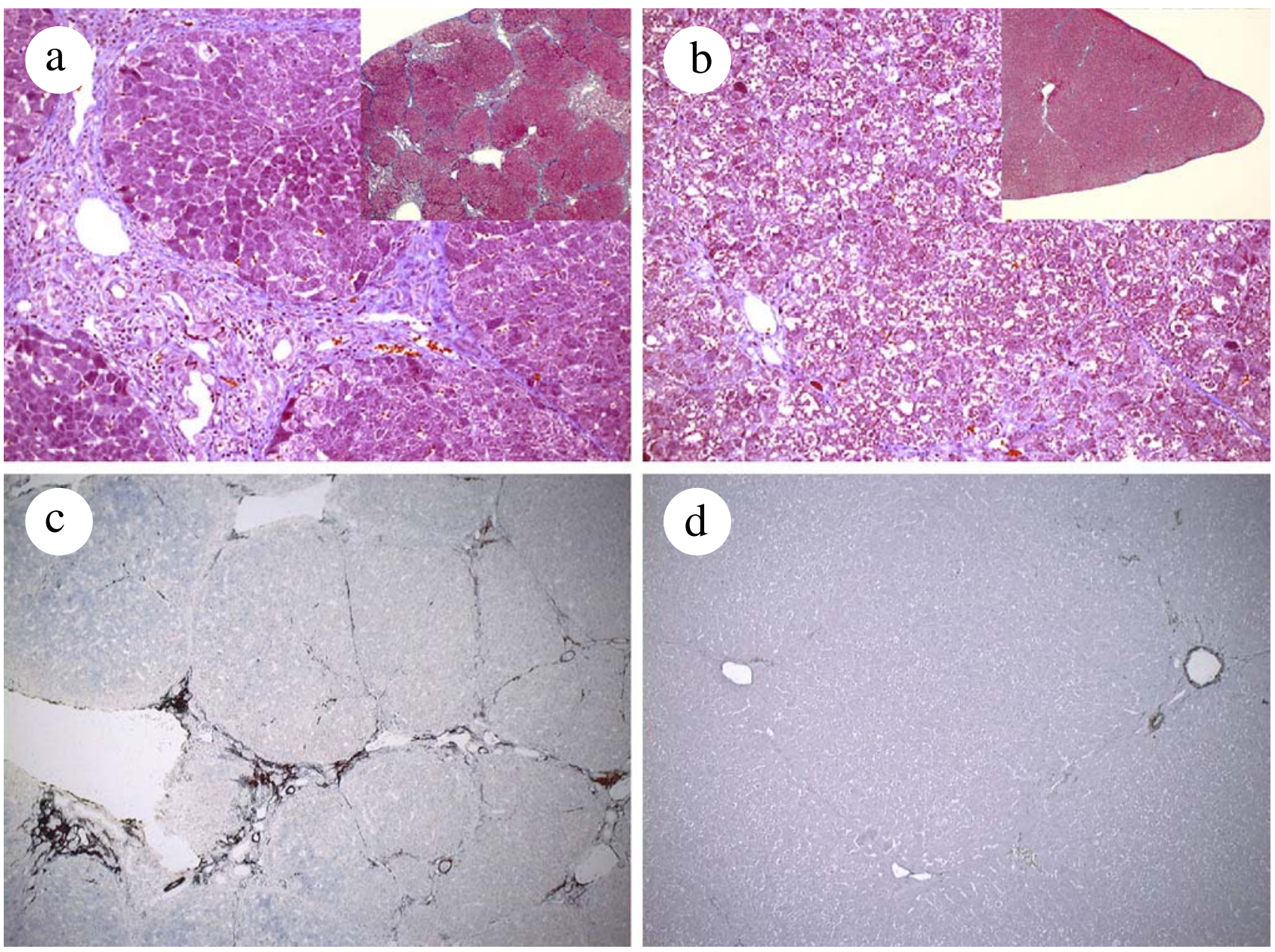

Fig. 3. Liver tissues treated with thioacetamide $(200 \mathrm{mg} / \mathrm{kg})$ for 7 weeks were stained with Masson's trichrome at 2 weeks after the adenoviral infections (a, b). Liver tissues were collected from control Ad5LacZ-infected (a) or Ad5MMP-1 infected (b) rats. Fibrous tissues were markedly attenuated with Ad5MMP-1 infection (b). Immunostaining against $\alpha$-smooth muscle actin $(\alpha$-SMA) was also performed in the liver from rats treated with TAA $(200 \mathrm{mg} / \mathrm{kg})$ for 7 weeks (c and d). Ad5LacZ-infected (c) and Ad5MMP-1-infected (d) livers at 2 weeks after the infection are shown. $\alpha$-SMA-positive area was remarkably reduced with Ad5MMP-1 infection (d). Figures were modified from ref. 46 (Gastroenterology 124: 445-58, 2003).

hepatocyte proliferation directly. Alternatively, it is possible in our model that several growth factors bound to hepatic ECM, such as hepatocyte growth factor (99), are freed from ECM by MMP-1 overexpression and that the activated growth factors facilitate hepatocyte proliferation. Indeed, this proliferative response of hepatocytes is not specific to the fibrotic liver, because we have observed the same proliferative effect of MMP-1 on hepatocytes when MMP-1 was expressed in normal rat livers (96).

ECM-cross linking has been implicated in the mechanism for the limited resolution of advanced liver fibrosis (30). Interestingly, it has been reported that the degradation of this form of ECM-cross linking can be achieved by MMP-1 (30). Thus, gene delivery of MMP-1, an interstitial collagenase, seems to offer several advantages for the treatment of advanced liver fibrosis, or cirrhosis.

A similar approach using gene delivery of MMP-8, human neutrophil collagenase, has been reported in animal models (94). In that experiment, liver fibrosis induced by $\mathrm{CCl}_{4}$ or bile duct ligation was ameliorated by the adenoviral gene transfer of MMP-8, and was accompanied by improved ascites and gastric varices. Meanwhile, adenoviral gene transfer with human urokinase-type plasminogen activator (uPA) also reversed experimental rat liver fibrosis inducing collagenase expression (100). Considering these experimental data by us and others, gene delivery of interstitial collagenases seems promising for the treatment of advanced cirrhosis in humans. However, persistent overexpression of interstitial collagenases in the liver possibly digests normal architectures in addition to pathologically deposited ECM. Therefore, precisely controlled delivery of active interstitial MMPs may be necessary for developing a treatment for clinical use.

\section{STRATEGIES TO ANTAGONIZE TIMP}

For the purpose of antagonizing the excess amounts of TIMPs in liver fibrosis, some strategies, employing an antiTIMP antibody or mutant MMP, have been reported. In the former report, an anti-TIMP antibody successfully decreased $\mathrm{HSC}$ activation and attenuated fibrosis in a $\mathrm{CCl}_{4}$-induced rat liver fibrosis (101). In the latter report, mutant MMP was delivered into a $\mathrm{CCl}_{4}$-induced mouse liver fibrosis (102). 
From the viewpoint that the balance between MMP and TIMPs is a pivotal parameter of the deposition and breakdown of the ECM, a catalytically inactive MMP-9 which still binds TIMP-1 was delivered as a specific antagonist of TIMP-1 in this study. MMP-9 mutants delivered into $\mathrm{CCl}_{4}$-induced experimental fibrotic livers using an adenoviral vector effectively suppressed liver fibrosis and inhibited mRNA expression of type I collagen. Reduced expression of $\alpha$-SMA, a marker of activated HSC, was also observed in the livers expressing MMP-9 mutants. This report has raised the possibility for the development of a new therapy without adverse side effects derived from MMP activity exogenously delivered.

\section{APPROACHES TO EFFICIENT AND SAFE DELIVERY OF MMP GENE}

Vectors that have been used for gene therapy are divided into two broad categories: viral and nonviral vectors. Viral vectors are derived from viruses with either RNA or DNA genomes and are represented as both integrating and nonintegrating vectors (103). RNA virus vectors are derived from retroviruses, and can be classified into oncoretroviruses, lentiviruses, and spumaviruses. Among the vectors derived from DNA viruses, the most prominent are those based on adenovirus (Ad) and the adeno-associated virus (AAV). As with any viral vector there are distinct advantages and disadvantages to its use. Retroviral vectors have shown to transduce and stably express transgenes for a long period, although the transduction efficiency is relatively low. Attractive properties of Ad vectors include their very efficient transduction of target cells in vitro and in vivo, but immunogenicity and toxicity of the vectors could make an obstacle against clinical use. Among the viral vector systems, AAV vector, which is derived from nonpathogenic human parvovirus, has been suspected as a promising one in treatment of many kinds of hereditary diseases.

The efficacy of MMP gene delivery using adenoviral vectors for the treatment of liver fibrosis has been reported as mentioned above $(93,94)$. However, the clinical use of adenoviral vectors is limited by the adverse effects of the virus vector itself, such as immunogenicity and toxicity as well as the possible mutagenesis of the cells transfected. Moreover, expression of MMP genes in the liver for a long period using viral vectors such as retroviral vectors or AAV vectors may possibly induce adverse side effect by over-degradation of ECM in normal architectures. Thus, it is important to create safe non-viral vectors with significant transduction efficiency and limited expression for clinical gene therapy of liver fibrosis.

Nonviral vectors should circumvent some of the problems occurring with viral vectors such as endogeneous virus recombination, oncogenic effects and unexpected immune response, and are categorized into two general groups: 1) naked DNA delivery by a physical method, such as electroporation, gene gun, ultrasound and hydrodynamic pressure and 2) delivery mediated by a chemical carrier such as cationic polymer and lipid (104). In consideration of selective MMP gene transfer into the liver, selective injection of naked DNA into the liver via the portal vein or the hepatic artery, or gene delivery using a chemical carrier possibly possess therapeutic potential. From such a view point, an interesting experiment where plasmid DNA encoding MMP-1 was delivered to streptozotocin-induced fibrotic kidneys using cationized gelatin hydrogels has been reported (105). In that study, in order to facilitate the sustained release of plasmid DNA, biodegradable hydrogels and microspheres were formulated from cationized gelatin prepared through aminization. Plasmid DNA was released from the cationized gelatin hydrogels as a result of hydrogel degradation. The hydroxylproline content in the murine fibrotic kidneys was effectively reduced when the gelatin microspheres incorporating plasmid MMP was administered. A combination of this kind of strategy and plasmid DNA of catalytically inactive MMPs may prove useful in treating advanced liver fibrosis in humans in the future.

\section{SUMMARY}

The removal of the causative factors is currently the most effective intervention in the treatment of liver fibrosis. Although experimental studies have revealed several targets to prevent fibrosis progression in rodents (17), whether complete regression from advanced cirrhosis is possible is still controversial, especially in humans. Therefore, the development of more effective and safe therapies against established liver fibrosis is critically important. In this review, the authors focused on MMP gene delivery that attempts to reset the imbalance between too little MMPs and too much TIMPs in advanced liver fibrosis. The delivery of interstitial MMPs into advanced liver fibrosis seems rational and is directed against the excess amount of deposited fibllilar collagens. More importantly, the data imply that even transient shifts in the imbalance between MMPs and TIMPs are sufficient for the resolution of advanced fibrosis, if the underlying causative stimuli have been successfully removed. The development of a safe and efficient MMP-delivering system may prove to be an attractive pharmaceutical target for the treatment of advanced liver fibrosis and cirrhosis.

\section{ACKNOWLEDGMENTS}

This work was supported in part by Grant-in-Aid for Scientific Research (B) (No. 14370394) to Y.I. from Japan Society for the Promotion of Science (JSPS). The authors thank Miss Aiko Wakahara and Miss Keiko Mitani for technical assistance.

\section{REFERENCES}

1. S. L. Friedman. Molecular regulation of hepatic fibrosis, an integrated cellular response to tissue injury. J. Biol. Chem. 275:2247-2250 (2000).

2. M. Pinzani, R. G. Romanelli, and S. Magli. Progression of fibrosis in chronic liver diseases: time to tally the score. J. Hepatol. 34:764-767 (2001).

3. D. Schuppan, J. J. Cho, J. D. Jia, and E. G. Hahn. Interplay of matrx and myofibroblasts during hepatic fibrogenesis. Curr. Top. Pathol. 93:205-218 (1999).

4. D. A. Brenner, T. Waterboer, S. K. Choi, J. N. Lindquist, B. Stefanovic, E. Burchardt, M. Yamauchi, A. Gillan, and R. A. Rippe. New aspects of hepatic fibrosis. J. Hepatol. 32:3238 (2000).

5. P. Gines, A. Cardenas, V. Arroyo, and J. Rodes. Management of cirrhosis and ascites. N. Engl. J. Med. 350:1646-1654 (2004). 
6. H. Popperand and S. Uenfriend. Hepatic fibrosis. Correlation of biochemical and morphologic investigations. Am. J. Med. 49:707-721 (1970).

7. J. F. Dufour, R. DeLellis, and M. M. Kaplan. Regression of hepatic fibrosis in hepatitis $\mathrm{C}$ with long-term interferon treatment. Dig. Dis. Sci. 43:2573-2576 (1998).

8. R. Sobesky, P. Mathurin, F. Charlotte, J. Moussalli, M. Olivi, M. Vidaud, V. Ratziu, P. Opolon, and T. Poynard. Modeling the impact of interferon alfa treatment on liver fibrosis progression in chronic hepatitis $\mathrm{C}$ : a dynamic view. The Multivirc Group. Gastroenterology 116:378-386 (1999).

9. P. Hammel, A. Couvelard, D. O’Toole, A. Ratouis, A. Sauvanet, J. F. Flejou, C. Degott, J. Belghiti, P. Bernades, D. Valla, P. Ruszniewski, and P. Levy. Regression of liver fibrosis after biliary drainage in patients with chronic pancreatitis and stenosis of the common bile duct. N. Engl. J. Med. 344:418-423 (2001).

10. A. Ahmedand and E. B. Keeffe. Hepatitis C virus and liver transplantation. Clin. Liver Dis. 5:1073-1090 (2001).

11. G. L. Davis, J. E. Albright, S. F. Cook, and D. M. Rosenberg. Projecting future complications of chronic hepatitis $\mathrm{C}$ in the United States. Liver Transpl. 9:331-338 (2003).

12. M. J. Arthur. Fibrogenesis II. Metalloproteinases and their inhibitors in liver fibrosis. Am. J. Physiol. Gastrointest. Liver Physiol. 279:G245-G249 (2000).

13. N. Kinnman and C. Houset. Peribiliary myofibroblasts in biliary type liver fibrosis. Front. Biosci. 7:d496-d503 (2002).

14. S. T. Magness, R. Bataller, L. Yang, and D. A. Brenner. A dual reporter gene transgenic mouse demonstrates heterogeneity in hepatic fibrogenic cell populations. Hepatology 40:1151-1159 (2004).

15. S. Milani, H. Herbst, D. Schuppan, K. Y. Kim, E. O. Riecken, and $\mathrm{H}$. Stein. Procollagen expression by nonparenchymal rat liver cells in experimental biliary fibrosis. Gastroenterology 98:175-184 (1990).

16. F. Marra. Hepatic stellate cells and the regulation of liver inflammation. J. Hepatol. 31:1120-1130 (1999).

17. R. Batallerand and D. A. Brenner. Hepatic stellate cells as a target for the treatment of liver fibrosis. Semin. Liver Dis. 21:437-451 (2001)

18. J. S. Duffield, S. J. Forbes, C. M. Constandinou, S. Clay, M. Partolina, S. Vuthoori, S. Wu, R. Lang, and J. P. Iredale. Selective depletion of macrophages reveals distinct, opposing roles during liver injury and repair. J. Clin. Invest. 115:56-65 (2005).

19. H. Emonard and J. A. Emonard. Matrix metalloproteinases. A review. Cell. Mol. Biol. 36:131-153 (1990).

20. J. M. Freije, I. Diez-Itza, M. Balbin, L. M. Sanchez, R. Blasco, J. Tolivia, and C. Lopez-Otin. Molecular cloning and expression of collagenase-3, a novel human matrix metalloproteinase produced by breast carcinomas. J. Biol. Chem. 269:16766-16773 (1994).

21. A. M. Preaux, A. Mallat, J. T. Nhieu, M. P. D'Ortho, R. M. Hembry, and P. Mavier. Matrix metalloproteinase-2 activation in human hepatic fibrosis regulation by cell-matrix interactions. Hepatology 30:944-950 (1999).

22. S. Milani, H. Herbst, D. Schuppan, C. Grappone, G. Pellegrini, M. Pinzani, A. Casini, A. Calabro, G. Ciancio, F. Stefanini, et al. Differential expression of matrix-metalloproteinase-1 and -2 genes in normal and fibrotic human liver. Am. J. Pathol. 144:528-537 (1994).

23. A. E. Kossakowska, D. R. Edwards, S. S. Lee, L. S. Urbanski, A. L. Stabbler, C. L. Zhang, B. W. Phillips, Y. Zhang, and S. J. Urbanski. Altered balance between matrix metalloproteinases and their inhibitors in experimental biliary fibrosis. Am. J. Pathol. 153:1895-1902 (1998).

24. J. P. Iredale, G. Murphy, R. M. Hembry, S. L. Friedman, and M. J. Arthur. Human hepatic lipocytes synthesize tissue inhibitor of metalloproteinases-1. Implications for regulation of matrix degradation in liver. J. Clin. Invest. 90:282-287 (1992).

25. Y. Murawaki, H. Yamamoto, H. Kawasaki, and H. Shima. Serum tissue inhibitor of metalloproteinases in patients with chronic liver disease and with hepatocellular carcinoma. Clin. Chim. Acta 218:47-58 (1993).
26. J. J. Maherand and D. M. Bissell. Cell-matrix interactions in liver. Semin. Cell Biol. 4:189-201 (1993).

27. H. Yoshiji, S. Kuriyama, J. Yoshii, Y. Ikenaka, R. Noguchi, T. Nakatani, H. Tsujinoue, K. Yanase, T. Namisaki, H. Imazu, and H. Fukui. Tissue inhibitor of metalloproteinases-1 attenuates spontaneous liver fibrosis resolution in the transgenic mouse. Hepatology 36:850-860 (2002).

28. F. R. Murphy, R. Issa, X. Zhou, S. Ratnarajah, H. Nagase, M. J. Arthur, C. Benyon, and J. P. Iredale. Inhibition of apoptosis of activated hepatic stellate cells by tissue inhibitor of metalloproteinase- 1 is mediated via effects on matrix metalloproteinase inhibition: implications for reversibility of liver fibrosis J. Biol. Chem. 277:11069-11076 (2002).

29. J. P. Iredale, R. C. Benyon, J. Pickering, M. McCullen, M. Northrop, S. Pawley, C. Hovell, and M. J. Arthur. Mechanisms of spontaneous resolution of rat liver fibrosis. Hepatic stellate cell apoptosis and reduced hepatic expression of metalloproteinase inhibitors. J. Clin. Invest. 102:538-549 (1998).

30. R. Issa, X. Zhou, C. M. Constandinou, J. Fallowfield, H. Millward-Sadler, M. D. Gaca, E. Sands, I. Suliman, N. Trim, A. Knorr, M. J. Arthur, R. C. Benyon, and J. P. Iredale. Spontaneous recovery from micronodular cirrhosis: evidence for incomplete resolution associated with matrix cross-linking. Gastroenterology 126:1795-1808 (2004).

31. M. J. Arthur. Reversibility of liver fibrosis and cirrhosis following treatment for hepatitis C. Gastroenterology 122:1525-1528 (2002).

32. R. Issa, E. Williams, N. Trim, T. Kendall, M. J. Arthur, J. Reichen, R. C. Benyon, and J. P. Iredale. Apoptosis of hepatic stellate cells: involvement in resolution of biliary fibrosis and regulation by soluble growth factors. Gut 48:548557 (2001).

33. M. C. Wright, R. Issa, D. E. Smart, N. Trim, G. I. Murray, J. N. Primrose, M. J. Arthur, J. P. Iredale, and D. A. Mann. Gliotoxin stimulates the apoptosis of human and rat hepatic stellate cells and enhances the resolution of liver fibrosis in rats. Gastroenterology 121:685-698 (2001).

34. P. Mathurin, V. Duchatelle, M. J. Ramond, C. Degott, P. Bedossa, S. Erlinger, J. P. Benhamou, J. C. Chaput, B. Rueff, and T. Poynard. Survival and prognostic factors in patients with severe alcoholic hepatitis treated with prednisolone. Gastroenterology 110:1847-1853 (1996).

35. H. C. Mitchison, J. M. Palmer, M. F. Bassendine, A. J. Watson, C. O. Record, and O. F. James. A controlled trial of prednisolone treatment in primary biliary cirrhosis. Three-year results. J. Hepatol. 15:336-344 (1992).

36. D. Kershenobich, F. Vargas, G. Garcia-Tsao, R. Perez Tamayo, M. Gent, and M. Rojkind. Colchicine in the treatment of cirrhosis of the liver. N. Engl. J. Med. 318:1709-1713 (1988).

37. A. Rambaldi and C. Gluud. Colchicine for alcoholic and nonalcoholic liver fibrosis and cirrhosis. Cochrane Database Syst. Rev. CD002148 (2001).

38. L. Ryhanen, F. Stenback, L. Ala-Kokko, and E. R. Savolainen. The effect of malotilate on type III and type IV collagen, laminin and fibronectin metabolism in dimethylnitrosamineinduced liver fibrosis in the rat. J. Hepatol. 24:238-245 (1996).

39. J. Fort, F. Oberti, C. Pilette, N. Veal, Y. Gallois, O. Douay, C. Rousselet, J. Rosenbaum, and P. Cales. Antifibrotic and hemodynamic effects of the early and chronic administration of octreotide in two models of liver fibrosis in rats. Hepatology 28:1525-1531 (1998).

40. Y. Iimuro, R. M. Gallucci, M. I. Luster, H. Kono, and R. G. Thurman. Antibodies to tumor necrosis factor alfa attenuate hepatic necrosis and inflammation caused by chronic exposure to ethanol in the rat. Hepatology 26:1530-1537 (1997).

41. R. Bruck, H. Shirin, R. Hershkoviz, O. Lider, G. Kenet, H. Aeed, Z. Matas, L. Zaidel, and Z. Halpern. Analysis of Arg-Gly-Asp mimetics and soluble receptor of tumour necrosis factor as therapeutic modalities for concanavalin A induced hepatitis in mice. Gut 40:133-138 (1997).

42. S. Naveau, S. Chollet-Martin, S. Dharancy, P. Mathurin, P. Jouet, M. A. Piquet, T. Davion, F. Oberti, P. Broet, and D. Emilie. A double-blind randomized controlled trial of 
infliximab associated with prednisolone in acute alcoholic hepatitis Hepatology 39:1390-1397 (2004).

43. N. Enomoto, Y. Takei, M. Hirose, K. Ikejima, H. Miwa, T. Kitamura, and N. Sato. Thalidomide prevents alcoholic liver injury in rats through suppression of Kupffer cell sensitization and TNF-alpha production. Gastroenterology 123:291-300 (2002).

44. P. Muriel, E. Fernandez-Martinez, V. Perez-Alvarez, F. LaraOchoa, S. Ponce, J. Garcia, M. Shibayama, and V. Tsutsumi. Thalidomide ameliorates carbon tetrachloride induced cirrhosis in the rat. Eur. J. Gastroenterol. Hepatol. 15:951-957 (2003).

45. R. Mancini, A. Benedetti, and A. M. Jezequel. An interleukin1 receptor antagonist decreases fibrosis induced by dimethylnitrosamine in rat liver. Virchows Arch. 424:25-31 (1994).

46. D. R. Nelson, Z. Tu, C. Soldevila-Pico, M. Abdelmalek, H. Zhu, Y. L. Xu, R. Cabrera, C. Liu, and G. L. Davis. Longterm interleukin 10 therapy in chronic hepatitis $C$ patients has a proviral and anti-inflammatory effect. Hepatology 38:859-868 (2003).

47. G. Svegliati Baroni, L. D'Ambrosio, G. Ferretti, A. Casini, A. SarioDi, R. Salzano, F. Ridolfi, S. Saccomanno, A. M. Jezequel, and A. Benedetti. Fibrogenic effect of oxidative stress on rat hepatic stellate cells. Hepatology 27:720-726 (1998).

48. M. Parola, G. Leonarduzzi, F. Biasi, E. Albano, M. E. Biocca, G. Poli, and M. U. Dianzani. Vitamin E dietary supplementation protects against carbon tetrachloride-induced chronic liver damage and cirrhosis. Hepatology 16:1014-1021 (1992).

49. K. E. Brown, J. E. Poulos, L. Li, A. M. Soweid, G. A. Ramm, R. O'Neill, R. S. Britton, and B. R. Bacon. Effect of vitamin E supplementation on hepatic fibrogenesis in chronic dietary iron overload. Am. J. Physiol. 272:G116-G123 (1997).

50. K. Houglum, A. Venkataramani, K. Lyche, and M. Chojkier. A pilot study of the effects of d-alpha-tocopherol on hepatic stellate cell activation in chronic hepatitis C. Gastroenterology 113:1069-1073 (1997).

51. C. S. Lieber, M. A. Leo, S. I. Aleynik, M. K. Aleynik, and L. M. DeCarli. Polyenylphosphatidylcholine decreases alcoholinduced oxidative stress in the baboon. Alcohol Clin. Exp. Res. 21:375-379 (1997).

52. S. I. Aleynik, M. A. Leo, X. Ma, M. K. Aleynik, and C. S. Aleynik. Polyenylphosphatidylcholine prevents carbon tetrachloride-induced lipid peroxidation while it attenuates liver fibrosis. J. Hepatol. 27:554-561 (1997).

53. J. D. Jia, M. Bauer, J. J. Cho, M. Ruehl, S. Milani, G. Boigk, E. O. Riecken, and D. Schuppan. Antifibrotic effect of silymarin in rat secondary biliary fibrosis is mediated by downregulation of procollagen alpha1(I) and TIMP-1 J. Hepatol. 35:392-398 (2001).

54. K. Y. Kim, T. Rhim, I. Choi, and S. S. Kim. N-acetylcysteine induces cell cycle arrest in hepatic stellate cells through its reducing activity. J. Biol. Chem. 276:40591-40598 (2001).

55. H. Okuyama, Y. Shimahara, N. Kawada, S. Seki, D. B. Kristensen, K. Yoshizato, N. Uyama, and Y. Yamaoka. Regulation of cell growth by redox-mediated extracellular proteolysis of platelet-derived growth factor receptor beta J. Biol. Chem. 276:28274-28280 (2001).

56. M. Gasso, M. Rubio, G. Varela, M. Cabre, J. Caballeria, E. Alonso, R. Deulofem, J. Camps, A. Gimenez, M. Pajares, A. Pares, J. M. Mato, and J. Rodes. Effects of S-adenosylmethionine on lipid peroxidation and liver fibrogenesis in carbon tetrachloride-induced cirrhosis. J. Hepatol. 25:200-205 (1996).

57. A. Pares, R. Planas, M. Torres, J. Caballeria, J. M. Viver, D. Acero, J. Panes, J. Rigau, J. Santos, and J. Rodes. Effects of silymarin in alcoholic patients with cirrhosis of the liver: results of a controlled, double-blind, randomized and multicenter trial. J. Hepatol. 28:615-621 (1998).

58. M. Pinzani, L. Gesualdo, G. M. Sabbah, and H. E. Abboud. Effects of platelet-derived growth factor and other polypeptide mitogens on DNA synthesis and growth of cultured rat liver fat-storing cells. J. Clin. Invest. 84:1786-1793 (1989).

59. X. J. Liu, L. Yang, Y. Q. Mao, Q. Wang, M. H. Huang, Y. P. Wang, and H. B. Wu. Effects of the tyrosine protein kinase inhibitor genistein on the proliferation, activation of cultured rat hepatic stellate cells. World J. Gastroenterol. 8:739-745 (2002).
60. H. Yoshiji, R. Noguchi, S. Kuriyama, Y. Ikenaka, J. Yoshii, K. Yanase, T. Namisaki, M. Kitade, T. Masaki, and H. Fukui. Imatinib mesylate (STI-571) attenuates liver fibrosis development in rats. Am. J. Physiol. Gastrointest. Liver Physiol. 288:G907-G913 (2005).

61. E. Borkham-Kamphorst, J. Herrmann, D. Stoll, J. Treptau, A. M. Gressner, and R. Weiskirchen. Dominant-negative soluble PDGF-beta receptor inhibits hepatic stellate cell activation and attenuates liver fibrosis. Lab. Invest. 84:766777 (2004).

62. F. Marra, A. Gentilini, M. Pinzani, G. G. Choudhury, M. Parolfsa, H. Herbst, M. U. Dianzani, G. Laffi, H. E. Abboud, and P. Gentilini. Phosphatidylinositol 3-kinase is required for platelet-derived growth factor's actions on hepatic stellate cells. Gastroenterology 112:1297-1306 (1997).

63. A. Caligiuri, R. M. FrancoDe, R. G. Romanelli, A. Gentilini, M. Meucci, P. Failli, L. Mazzetti, K. Rombouts, A. Geerts, M. Vanasia, P. Gentilini, F. Marra, and M. Pinzani. Antifibrogenic effects of canrenone, an antialdosteronic drug, on human hepatic stellate cells. Gastroenterology 124:504-520 (2003).

64. S. Reif, A. Lang, J. N. Lindquist, Y. Yata, E. Gabele, A. Scanga, D. A. Brenner, and R. A. Rippe. The role of focal adhesion kinase-phosphatidylinositol 3-kinase-akt signaling in hepatic stellate cell proliferation and type I collagen expression. J. Biol. Chem. 278:8083-8090 (2003).

65. S. Reif, B. Weis, H. Aeed, M. Gana-Weis, L. Zaidel, Y. Avni, R. G. Romanelli, M. Pinzani, Y. Kloog, and R. Bruck. The Ras antagonist, farnesylthiosalicylic acid (FTS), inhibits experimentally-induced liver cirrhosis in rats. J. Hepatol. 31:1053-1061 (1999).

66. H. Iwamoto, M. Nakamuta, S. Tada, R. Sugimoto, M. Enjoji, and H. Nawata. A p160ROCK-specific inhibitor, Y-27632, attenuates rat hepatic stellate cell growth. J. Hepatol. 32:762-770 (2000).

67. T. Murata, S. Arii, T. Nakamura, A. Mori, T. Kaido, H. Furuyama, K. Furumoto, T. Nakao, N. Isobe, and M. Imamura. Inhibitory effect of Y-27632, a ROCK inhibitor, on progression of rat liver fibrosis in association with inactivation of hepatic stellate cells. J. Hepatol. 35:474-481 (2001).

68. M. Okuno, K. Akita, H. Moriwaki, N. Kawada, K. Ikeda, K. Kaneda, Y. Suzuki, and S. Kojima. Prevention of rat hepatic fibrosis by the protease inhibitor, camostat mesilate, via reduced generation of active TGF-beta. Gastroenterology 120:1784-1800 (2001).

69. J. George, D. Roulot, V. E. Koteliansky, and D. M. Bissell. In vivo inhibition of rat stellate cell activation by soluble transforming growth factor beta type II receptor: a potential new therapy for hepatic fibrosis. Proc. Natl. Acad. Sci. USA 96:12719-12724 (1999).

70. Z. Qi, N. Atsuchi, A. Ooshima, A. Takeshita, and H. Ueno. Blockade of type beta transforming growth factor signaling prevents liver fibrosis and dysfunction in the rat. Proc. Natl. Acad. Sci. USA 96:2345-2349 (1999).

71. M. Arias, S. Sauer-Lehnen, J. Treptau, N. Janoschek, I. Theuerkauf, R. Buettner, A. M. Gressner, and R. Weiskirchen. Adenoviral expression of a transforming growth factor-betal antisense mRNA is effective in preventing liver fibrosis in bile-duct ligated rats. $B M C$ Gastroenterol. 3:29, 2003 (2003).

72. S. Dooley, J. Hamzavi, K. Breitkopf, E. Wiercinska, H. M. Said, J. Lorenzen, P. Ten Dijke, and A. M. Gressner. Smad7 prevents activation of hepatic stellate cells and liver fibrosis in rats. Gastroenterology 125:178-191 (2003).

73. Y. Matsuda, K. Matsumoto, T. Ichida, and T. Nakamura. Hepatocyte growth factor suppresses the onset of liver cirrhosis and abrogates lethal hepatic dysfunction in rats. J. Biochem. (Tokyo) 118:643-649 (1995).

74. T. Ueki, Y. Kaneda, H. Tsutsui, K. Nakanishi, Y. Sawa, R. Morishita, K. Matsumoto, T. Nakamura, H. Takahashi, E. Okamoto, and J. Fujimoto. Hepatocyte growth factor gene therapy of liver cirrhosis in rats. Nat. Med. 5:226-230 (1999).

75. R. Bataller, P. Gines, J. M. Nicolas, M. N. Gorbig, E. GarciaRamallo, X. Gasull, J. Bosch, V. Arroyo, and J. Rodes. Angiotensin II induces contraction and proliferation of human hepatic stellate cells. Gastroenterology 118:1149-1156 (2000).

76. H. S. Wei, D. G. Li, H. M. Lu, Y. T. Zhan, Z. R. Wang, X. Huang, J. Zhang, J. L. Cheng, and Q. F. Xu. Effects of AT1 
receptor antagonist, losartan, on rat hepatic fibrosis induced by CCl(4). World J. Gastroenterol. 6:540-545 (2000).

77. H. Yoshiji, S. Kuriyama, J. Yoshii, Y. Ikenaka, R. Noguchi, T. Nakatani, H. Tsujinoue, and H. Fukui. Angiotensin-II type 1 receptor interaction is a major regulator for liver fibrosis development in rats. Hepatology 34:745-750 (2001).

78. N. Kurikawa, M. Suga, S. Kuroda, K. Yamada, and H. Ishikawa. An angiotensin II type 1 receptor antagonist, olmesartan medoxomil, improves experimental liver fibrosis by suppression of proliferation and collagen synthesis in activated hepatic stellate cells. Br. J. Pharmacol. 139:1085-1094 (2003).

79. J. R. Jonsson, A. D. Clouston, Y. Ando, L. I. Kelemen, M. J. Horn, M. D. Adamson, D. M. Purdie, and E. E Powell. Angiotensin-converting enzyme inhibition attenuates the progression of rat hepatic fibrosis. Gastroenterology 121:148-155 (2001).

80. T. Niki, K. Rombouts, P. BleserDe, K. SmetDe, V. Rogiers, D. Schuppan, M. Yoshida, G. Gabbiani, and A. Geerts. A histone deacetylase inhibitor, trichostatin A, suppresses myofibroblastic differentiation of rat hepatic stellate cells in primary culture. Hepatology 29:858-867 (1999).

81. B. Saile, T. Knittel, N. Matthes, P. Schott, and G. Ramadori. CD95/CD95L-mediated apoptosis of the hepatic stellate cell. A mechanism terminating uncontrolled hepatic stellate cell proliferation during hepatic tissue repair. Am. J. Pathol. 151:1265$1272(1997)$

82. F. Oakley, N. Trim, C. M. Constandinou, W. Ye, A. M. Gray, G. Frantz, K. Hillan, T. Kendall, R. C. Benyon, D. A. Mann, and J. P. Iredale. Hepatocytes express nerve growth factor during liver injury: evidence for paracrine regulation of hepatic stellate cell apoptosis. Am. J. Pathol. 163:1849-1858 (2003).

83. F. Oakley, M. Meso, J. P. Iredale, K. Green, C. J. Marek, X. Zhou, M. J. May, H. Millward-Sadler, M. C. Wright, and D. A. Mann. Inhibition of inhibitor of kappaB kinases stimulates hepatic stellate cell apoptosis and accelerated recovery from rat liver fibrosis. Gastroenterology 128:108-120 (2005).

84. S. Reif, H. Aeed, Y. Shilo, R. Reich, Y. Kloog, Y. O. Kweon, and R. Bruck. Treatment of thioacetamide-induced liver cirrhosis by the Ras antagonist, farnesylthiosalicylic acid J. Hepatol. 41:235-241 (2004).

85. I. Sakaida, S. Terai, N. Yamamoto, K. Aoyama, T. Ishikawa, H. Nishina, and K. Okita. Transplantation of bone marrow cells reduces CCl4-induced liver fibrosis in mice. Hepatology 40:1304-1311 (2004).

86. R. Higashiyama, Y. Inagaki, Y. Y. Hong, M. Kushida, S. Nakao, M. Niioka, T. Watanabe, H. Okano, Y. Matsuzaki, G. Shiota, and I. Okazaki. Bone marrow-derived cells express matrix metalloproteinases and contribute to regression of liver fibrosis in mice. Hepatology 45:213-222 (2007).

87. S. J. Forbes, F. P. Russo, V. Rey, P. Burra, M. Rugge, N. A. Wright, and M. R. Alison. A significant proportion of myofibroblasts are of bone marrow origin in human liver fibrosis. Gastroenterology 126:955-963 (2004).

88. F. P. Russo, M. R. Alison, B. W. Bigger, E. Amofah, A. Florou, F. Amin, G. Bou-Gharios, R. Jeffery, J. P. Iredale, and S. J. Forbes. The bone marrow functionally contributes to liver fibrosis. Gastroenterology 130:1807-1821 (2006).

89. T. Kisseleva, H. Uchinami, N. Feirt, O. Quintana-Bustamante, J. C. Segovia, R. F. Schwabe, and D. A. Brenner. Bone marrow-derived fibrocytes participate in pathogenesis of liver fibrosis. J. Hepatol. 45:429-438 (2006).

90. I. R. Wanless, E. Nakashima, and M. Sherman. Regression of human cirrhosis. Morphologic features and the genesis of incomplete septal cirrhosis. Arch. Pathol. Lab. Med. 124:15991607 (2000).
91. R. C. Benyon, J. P. Iredale, S. Goddard, P. J. Winwood, and M. J. Arthur. Expression of tissue inhibitor of metalloproteinases 1 and 2 is increased in fibrotic human liver. Gastroenterology 110:821-831 (1996).

92. R. Visseand and H. Nagase. Matrix metalloproteinases and tissue inhibitors of metalloproteinases: structure, function, and biochemistry. Circ. Res. 92:827-839 (2003).

93. Y. Iimuro, T. Nishio, T. Morimoto, T. Nitta, B. Stefanovic, S. K. Choi, D. A. Brenner, and Y. Yamaoka. Delivery of matrix metalloproteinase-1 attenuates established liver fibrosis in the rat. Gastroenterology 124:445-458 (2003).

94. F. Siller-Lopez, A. Sandoval, S. Salgado, A. Salazar, M. Bueno, J. Garcia, J. Vera, J. Galvez, I. Hernandez, M. Ramos, E. AguilarCordova, and J. Armendariz-Borunda. Treatment with human metalloproteinase- 8 gene delivery ameliorates experimental rat liver cirrhosis. Gastroenterology 126:1122-1133 (2004).

95. A. Muller, F. Machnik, T. Zimmermann, and H. Schubert. Thioacetamide-induced cirrhosis-like liver lesions in rats-usefulness and reliability of this animal model. Exp. Pathol. 34:229-236 (1988).

96. T. Nishio, Y. Iimuro, T. Nitta, N. Harada, M. Yoshida, T. Hirose, N. Yamamoto, T. Morimoto, D. A. Brenner, and Y. Yamaoka. Increased expression of collagenase in the liver induces hepatocyte proliferation with cytoplasmic accumulation of beta-catenin in the rat. J. Hepatol. 38:468-475 (2003).

97. W. J. Lindblad, E. G. Schuetz, K. S. Redford, and P. S. Guzelian. Hepatocellular phenotype in vitro is influenced by biophysical features of the collagenous substratum. Hepatology 13:282-288 (1991).

98. B. Rana, D. Mischoulon, Y. Xie, N. L. Bucher, and S. R. Farmer. Cell-extracellular matrix interactions can regulate the switch between growth and differentiation in rat hepatocytes: reciprocal expression of $\mathrm{C} / \mathrm{EBP}$ alpha and immediate-early growth response transcription factors. Mol. Cell. Biol. 14:58585869 (1994).

99. D. Schuppan, M. Schmid, R. Somasundaram, R. Ackermann, M. Ruehl, T. Nakamura, and E. O. Riecken. Collagens in the liver extracellular matrix bind hepatocyte growth factor. Gastroenterology 114:139-152 (1998).

100. S. Salgado, J. Garcia, J. Vera, F. Siller, M. Bueno, A. Miranda, A. Segura, G. Grijalva, J. Segura, H. Orozco, R. HernandezPando, M. Fafutis, L. K. Aguilar, E. Aguilar-Cordova, and J. Armendariz-Borunda. Liver cirrhosis is reverted by urokinase-type plasminogen activator gene therapy. Mol. Ther. 2:545-551 (2000)

101. C. J. Parsons, B. U. Bradford, C. Q. Pan, E. Cheung, M. Schauer, A. Knorr, B. Krebs, S. Kraft, S. Zahn, B. Brocks, N. Feirt, B. Mei, M. S. Cho, R. Ramamoorthi, G. Roldan, P. Ng, P. Lum, C. Hirth-Dietrich, A. Tomkinson, and D. A. Brenner. Antifibrotic effects of a tissue inhibitor of metalloproteinase-1 antibody on established liver fibrosis in rats. Hepatology 40:1106-1115 (2004).

102. M. Roderfeld, R. Weiskirchen, S. Wagner, M. L. Berres, C. Henkel, J. Grotzinger, A. M. Gressner, S. Matern, and E. Roeb. Inhibition of hepatic fibrogenesis by matrix metalloproteinase-9 mutants in mice. FASEB J. 20:444-454 (2006).

103. I. M. Vermaand and M. D. Weitzman. Gene therapy: twentyfirst century medicine. Annu. Rev. Biochem. 74:711-738 (2005).

104. T. Niidomeand and L. Huang. Gene therapy progress and prospects: nonviral vectors. Gene Ther. 9:1647-1652 (2002).

105. T. Aoyama, S. Yamamoto, A. Kanematsu, O. Ogawa, and Y. Tabata. Local delivery of matrix metalloproteinase gene prevents the onset of renal sclerosis in streptozotocin-induced diabetic mice. Tissue Eng. 9:1289-1299 (2003). 